\title{
Sleep-Related Breathing Disorders: When CPAP Is Not Enough
}

\author{
Bernardo Selim ${ }^{1} \cdot$ Kannan Ramar ${ }^{1}$ \\ Accepted: 19 October 2020 / Published online: 4 November 2020 \\ (C) The American Society for Experimental NeuroTherapeutics, Inc. 2020
}

\begin{abstract}
Three decades ago, continuous positive airway pressure (CPAP) was introduced to treat obstructive sleep apnea (OSA). Shortly after, bilevel positive airway pressure devices (BPAP) that independently adjusted inspiratory and expiratory positive airway pressure were developed to treat complex sleep-related breathing disorders unresponsive to CPAP. Based on the bilevel positive airway pressure platform (hardware) governed by propriety algorithms (software), advanced modes of noninvasive ventilation (NIV) were developed to address complex cardiorespiratory pathophysiology beyond OSA. This review summarizes key aspects of different bilevel PAP therapies (BPAP with/without backup rate, adaptive servoventilation, and volume-assured pressure support) to treat common sleep-related hypoventilation disorders, treatment-emergent central sleep apnea, and central sleep apnea syndromes.
\end{abstract}

Key Words Bilevel positive airway pressure (BPAP) - Adaptive servoventilation (ASV) · Volume-assured pressure support (VAPS) $\cdot$ Sleep-related hypoventilation $\cdot$ Treatment-emergent central apnea $\cdot$ Central sleep apnea

\section{Introduction}

Collin Sullivan introduced continuous positive airway pressure (CPAP) as a therapeutic modality to treat obstructive sleep apnea (OSA) in 1981 [1]. CPAP provides a pneumatic splint to the pharyngeal airway preventing it from collapsing during sleep, along with improvement in lung volumes (i.e., functional residual capacity) and oxyhemoglobin saturation [2]. In 1990, Sanders and Kern described the treatment of OSA by "independently adjusted inspiratory and expiratory positive airway pressures" via mask interface. By installing a flow sensor (input), the device was able to correctly detect the patient's breath phase (inhalation $v s$ exhalation) to deliver a different therapeutic pressure during inhalation - inspiratory positive airway pressure (IPAP) - and during exhalationexpiratory positive airway pressure (EPAP) [3]. With the introduction of digital processing of the flow signal (input), current advanced bilevel devices have developed the capability to self-modulate IPAP and/or EPAP as well as to "time" the initiation and/or termination of each breath in synchrony

Bernardo Selim

selim.bernardo@mayo.edu

1 Pulmonary and Critical Care Division, Center for Sleep Medicine, Mayo Clinic, 200 First Street SW, Rochester, MN 55905, USA with patient's breathing. Different from CPAP, these advanced modes of bilevel positive airway pressure ventilation, collectively known as noninvasive ventilation (NIV), were developed to address complex cardiorespiratory pathophysiology beyond OSA [4] (Fig. 1A).

\section{Practical Pathophysiologic Approach to Sleep-Related Breathing Disorders}

The third edition of International Classification of Sleep Disorders - Diagnostic and Coding Manual (ICSD-3) has grouped the sleep-related breathing disorders (SRBD) into obstructive sleep apnea disorders (OSA), central sleep apnea syndromes (CSAS), and sleep-related hypoventilation disorders (alveolar hypoventilation) [5]. These disorders encompass a heterogeneous group of diseases with diverse pathophysiological mechanisms of which many patients may meet diagnostic criteria for more than one of them (Table 1).

In general, these breathing disorders can be grouped into two categories based upon their effect on partial pressure of carbon dioxide $\left(\mathrm{pCO}_{2}\right)$ balance, as reflected in arterial carbon dioxide tension $\left(\mathrm{PaCO}_{2}\right)$. Sleep-related hypoventilation disorders (alveolar hypoventilation) are associated with hypercapnia $\left(\mathrm{PaCO}_{2} \geq 45 \mathrm{mmHg}\right)$ due to ineffective ventilation $\left(\mathrm{CO}_{2}\right.$ elimination). Common causes of hypercapnic respiratory 
failure are increased lung ventilation-perfusion inequality and respiratory system load (e.g., chronic obstructive pulmonary disease), decreased respiratory drive (e.g., opioid intake), or inadequate respiratory muscle strength (e.g., neuromuscular disorders), or a combination of them. In contrast, CSAS are eucapnic $\left(\mathrm{PaCO}_{2} \leq 45 \mathrm{mmHg}\right)$ or even hypocapnic $\left(\mathrm{PaCO}_{2}<\right.$ 40) sleep-related breathing disorders characterized by intermittently diminished/increased or absent respiratory efforts (i.e., hypopneic, hyperpneic, and apneic phases) (e.g., Cheyne-Stokes respiration (CSR)) [6] (Table 1).

Treatment of these diverse disorders shares some basic principles. In general, if they are associated with underlying medical illnesses or medications, the treatment of the underlying condition may improve the sleep-related breathing disorder (e.g., cardiac therapy optimization by guideline-directed therapy of congestive heart failure). However, when correction of the underlying problem is not achieved, treatment of the underlying sleep-related breathing disorder is based on noninvasive positive airway pressure (PAP) therapy delivered either in the form of CPAP or bilevel positive airway pressure (bi-PAP) by portable devices via a facial mask. The latter is known under the generic name of NIV secondary to its capability to augment ventilation without the requirement for an invasive artificial airway (i.e., via intubation). NIV encompasses modes such as bilevel positive airway pressure (BPAP) with/out backup rate, adaptive servoventilation (ASV), and volume-assured pressure support (VAPS).

\section{Basic Components of Positive Airway Pressure Devices}

Positive airway pressure devices (hardware) are portable flow generators capable of delivering positive air pressure to a patient via a facial mask interface. PAP devices are basically composed of a turbine ("blower"), a respiratory circuit (a single or double hose), and a facial mask. Based on flow and pressure sensors located in the device (device input), a microprocessor-based controller (governed by propriety algorithms) is constantly adjusting the turbine speed in order to reach a preset positive pressure (device output) chosen by the provider (Fig. 1B).

Based on their settings (mode), PAP devices may either deliver a single, continuous pressure (CPAP) mode at all times or a higher inspiratory pressure (IPAP) and a lower expiratory pressure (EPAP) in the form of BPAP mode, thereby supporting and/or augmenting patient's breath (tidal volumes) in addition to stabilizing the patency of the upper airway and, hence, ventilation. Depending on the type of software (modes), BPAP modes may interact differently with the breathing pattern, adjusting pressure accordingly using propriety algorithms (decision paths) designed to achieve a specific respiratory assistance (e.g., ventilation support in alveolar hypoventilation or countercyclical compensatory respiratory support in Cheyne-Stokes respiration) [4].

\section{Type of Bilevel Positive Airway Pressure Modes}

\section{Basic BPAP Modes: BPAP-S and BPAP-ST}

BPAP mode may cycle between two pressures, a higher pressure, i.e., IPAP, and a lower pressure, i.e., EPAP, in response to the patient's respiratory effort (flow) or time to breathe. While the IPAP augments inspiration, the EPAP provides a pneumatic splint to maintain upper airway patency and maintains/improves expiratory residual volume and thereby improves the lung oxygen reservoir. The difference between the two pressures (IPAP and EPAP), called pressure support or delta pressure, contributes to improved ventilation through tidal breath augmentation. The larger the pressure support, the larger the tidal volume (depth of breath) that is generated which will help with ventilation to reduce $\mathrm{PaCO}_{2}$. However, for a given patient, the tidal volume generated by BPAP is not fixed and depends on the interaction between the preset pressure in the device, inspiratory time and effort, and the dynamic characteristics of the respiratory system (resistance and compliance) (Fig. 2A, Table 2).

Based on the level of interaction with the patient's spontaneous respiratory effort, BPAP may be delivered in S (spontaneous), ST (spontaneous/timed), and T (timed) modes. In S mode, the device senses when the patient is inhaling and exhaling and supplies the IPAP and EPAP accordingly. In the ST mode, the device in addition to supporting and/or augmenting breaths initiated by the patient, it also provides additional breaths should the patient's breath rate fall below the preset backup respiratory rate (RR) (Fig. 2B, Table 2). Although rarely used, in $\mathrm{T}$ mode, a fixed breath rate and duration are applied by the device based on patient's lack of respiratory drive.

\section{Volume-Assured Pressure Support}

VAPS mode tracks spontaneous respiratory breath and expiratory tidal volume, proportionally adjusting IPAP and/or the backup respiratory rate, with subsequent augmentation of breathing when needed to reach a respiratory target set by the provider. These respiratory targets could be either expiratory tidal volume or alveolar ventilation. Tidal volume is the total amount of air inhaled (and exhaled) with each breath, a third of which remains in the conducting airways (anatomical dead space) and the rest reaches the alveoli for oxygen and carbon dioxide gas exchange. Alveolar ventilation (respiratory rate multiplied by the tidal volume minus the anatomical dead space volume, i.e., the alveolar volume) is the amount of 
Fig. 1 (A) CPAP $v s$ NIV in respiratory support. (B)

Components of a single-limb circuit NIV. CPAP = continuous positive airway pressure; $\mathrm{FRC}=$ functional residual capacity; NIV $=$ noninvasive ventilation; $\mathrm{Vt}=$ tidal volume; $\mathrm{RR}=$ respiration rate; UA = upper airway

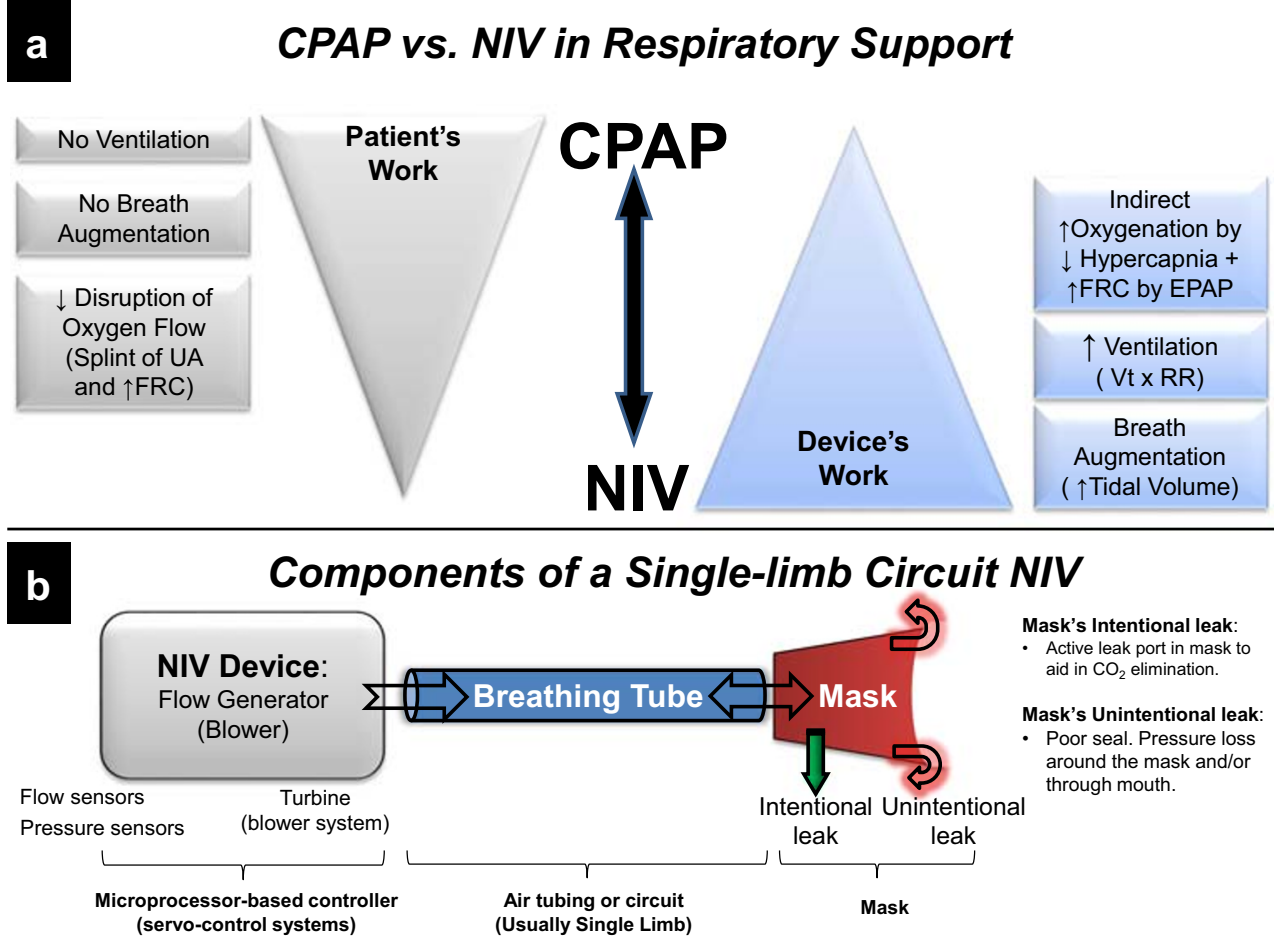

tidal volume that reaches the alveoli each minute, while minute ventilation (tidal volume that includes the anatomical dead space volume) is the total tidal volume multiplied by the respiratory rate. In patients with inadequate ventilation due to a decrease in respiratory drive (e.g., use of opioids or a brainstem lesion affecting the respiratory control center), a backup respiratory rate from the VAPS will supply additional breaths to reach adequate minute ventilation. An auto-EPAP function is also available in more recent device models to selfadjust to upper airway resistance to maintain upper airway patency [7] (Fig. 2C, Table 2).

\section{Adaptive Servoventilation}

The ASV device supports breathing in a countercyclical compensatory fashion (counterbalance proportional system). When ventilation decreases, the ASV mode may provide a higher respiratory support (i.e., minute ventilation or peak flow) by increasing inspiratory pressure support and/or respiratory rate. When ventilation returns to a more stable breathing pattern, this mode lowers support to a minimum. As the device detects stronger breath, it automatically lowers the pressure support provided [7]. This "on demand" breathing support allows a dampening effect on respiratory drive fluctuations and is particularly useful in periodic breathing secondary to a highly unstable respiratory drive system (high loop gain) as in patients with CSR. Loop gain is an engineering term that describes in pulmonary physiology the degree of response, in this case, of the respiratory control system, after a ventilatory disturbance results in minimal changes of nocturnal $\mathrm{PaCO}_{2}$. Therefore, if the loop gain is high in a particular system (or patient), there is a higher variability in the ventilatory (both high and low ventilation) response to minimal changes in $\mathrm{PaCO} 2$, resulting in respiratory instability. Disorders such as Cheyne-Stokes respiration (CSR) in congestive heart failure and high-altitude central sleep apnea are examples of this high loop gain respiratory control system [7, 8] (Fig. 2D, Table 2).

\section{Brief Literature Review on Noninvasive Ventilation Therapy to Treat Various Sleep-Related Breathing Disorders}

\section{Sleep-Related Hypoventilation Disorders}

As described in "Practical Pathophysiologic Approach to Sleep-Related Breathing Disorders," this group of disorders is defined by an elevated nocturnal $\mathrm{PaCO}_{2}$ level (> $45 \mathrm{mmHg}$ ), which may extend into the daytime. The main respiratory abnormality resulting in ventilatory failure may reside at any point along the brainstem respiratory control center (e.g., congenital/acquired central alveolar hypoventilation syndrome, opioids' side effects), to the respiratory motor output unit (e.g., neuromuscular diseases), and to the thoracicpulmonary unit (e.g., thoracic cage disorders, obstructive lung diseases such as COPD). 
Table 1 Sleep-related hypoventilation disorders and central sleep apnea syndromes

\begin{tabular}{|c|c|c|}
\hline Pathophysiology & Disorders & Notes \\
\hline \multirow[t]{4}{*}{$\begin{array}{l}\text { High nocturnal carbon dioxide } \\
\text { (sleep-related hypoventilation } \\
\text { disorders) }\end{array}$} & $\begin{array}{l}\text { Ventilatory control abnormalities } \\
\text { - e.g., congenital central alveolar } \\
\text { hypoventilation syndrome } \\
\text { (CCAHS) }\end{array}$ & Ventilatory control is affected by mutations in the PHOX2B gene. \\
\hline & $\begin{array}{l}\text { Neuromuscular disorders } \\
\text { • e.g., amyotrophic lateral sclerosis } \\
\text { (ALS) }\end{array}$ & $\begin{array}{l}\text { Inability to translate ventilatory center output into appropriate output by the } \\
\text { neuromuscular apparatus, thus rendering ventilatory control ineffective. }\end{array}$ \\
\hline & $\begin{array}{l}\text { Chest wall abnormalities } \\
\text { - e.g., kyphoscoliosis or obesity } \\
\text { hypoventilation syndrome }\end{array}$ & $\begin{array}{l}\text { Increased work of breathing and limited lung expansion due to thoracic } \\
\text { cage abnormalities, such as skeletal rigidity or excessive load from } \\
\text { adipose tissue blunts the intended response to } \mathrm{CO}_{2} \text {. }\end{array}$ \\
\hline & $\begin{array}{l}\text { Lung disorders } \\
\text { • e.g., chronic obstructive lung } \\
\text { disease (COPD) I }\end{array}$ & $\begin{array}{l}\text { In COPD, mechanical effectiveness of ventilation is compromised by } \\
\text { ventilation-perfusion inequality, respiratory muscle dysfunction, and } \\
\text { changes in chemosensitivity of the respiratory centers. During sleep, } \\
\text { ventilation failure is particularly evident during REM sleep, when per- } \\
\text { sistence of ventilation is primarily dependent on diaphragm activity and } \\
\text { central (nonmetabolic) respiratory drive. }\end{array}$ \\
\hline \multirow[t]{4}{*}{$\begin{array}{l}\text { Normal or reduced nocturnal carbon } \\
\text { dioxide (central sleep apnea } \\
\text { syndromes) }\end{array}$} & $\begin{array}{l}\text { Treatment-emergent central sleep } \\
\text { apnea }\end{array}$ & $\begin{array}{l}\text { High loop gain induced by CPAP therapy for obstructive sleep apnea } \\
\text { syndrome. OSA phenotype characterized by ventilatory control center } \\
\text { instability in response to minor } \mathrm{CO}_{2} \text { fluctuations induced by CPAP } \\
\text { therapy. }\end{array}$ \\
\hline & $\begin{array}{l}\text { Central sleep apnea with } \\
\text { Cheyne-Stokes breathing }\end{array}$ & $\begin{array}{l}\text { This disorder is primarily seen in patients with congestive heart failure. } \\
\text { High loop gain with feedback delays induced by poor cardiac output. } \\
\text { Patients exhibit enhanced ventilatory drive leading to cyclic over and } \\
\text { undershoot of ventilation (crescendo and decrescendo breathing patterns } \\
\text { interspaced by apneic events). }\end{array}$ \\
\hline & $\begin{array}{l}\text { Central sleep apnea due to } \\
\text { high-altitude periodic breathing }\end{array}$ & $\begin{array}{l}\text { High loop gain induced by hypoxemia as a result of decreased fractional } \\
\text { oxygen concentration at high altitude. }\end{array}$ \\
\hline & $\begin{array}{l}\text { Central sleep apnea due to } \\
\text { medications or substances } \\
\text { - e.g., opioids }\end{array}$ & $\begin{array}{l}\text { Loop gain is variable, and opioid effects on the pre-Bötzinger complex } \\
\text { result in unpredictable behavior of the ventilatory control center. }\end{array}$ \\
\hline
\end{tabular}

\section{Obesity Hypoventilation Syndrome}

Obesity hypoventilation syndrome (OHS) is defined by the triad of obesity (BMI $\left.\geq 30 \mathrm{~kg} / \mathrm{m}^{2}\right)$, daytime hypercapnia $\left(\mathrm{PaCO}_{2} \geq\right.$ $45 \mathrm{mmHg}$ ), and sleep-disordered breathing often present in the form of OSA. It is a diagnosis of exclusion, when other alternative explanations for hypoventilation (e.g., chronic obstructive pulmonary disease, medication/substance such as opioids, or neuromuscular disease) have been ruled out [5]. Nearly 70\% of OHS patients have severe OSA [9]. The remaining patients have nonobstructive sleep hypoventilation with no or mild OSA. As per the American Academy of Sleep Medicine (AASM), hypoventilation is defined by $\mathrm{PaCO}_{2}>55 \mathrm{mmHg}$ for $>10$ min or an increase in $\mathrm{PaCO}_{2}>10 \mathrm{mmHg}$ compared to an awake supine value $>50 \mathrm{mmHg}$ for $>10 \mathrm{~min}$ [5].

Pathophysiology in OHS The pathophysiology is not completely known. The implicated mechanisms leading to daytime hypercapnia are probably a combination of impairment in respiratory mechanics with increase in mechanical load due to obesity and blunted respiratory drive due to central resistance to leptin as a respiratory stimulant. Furthermore,
OSA with relatively long-lasting apneas and hypopneas may also contribute to insufficient postevent ventilatory compensation with subsequent hypoventilation during sleep, particularly prominent during rapid eye movement (REM) sleep [10, 11]. Additional understanding of the pathophysiologic pathway may help to characterize OHS phenotypes and thereby able to predict the responses to the different modalities of positive airway pressure (PAP) therapies.

For therapeutic purposes, two OHS phenotypes can be identified: patients with predominant severe OSA and patients with milder OSA but severe hypercapnia and typical REM sleep hypoventilation secondary to decreased respiratory drive. The former phenotype is likely to respond to CPAP and the latter (sometimes referred as "true Pickwickian syndrome") is likely to respond to NIV. Left untreated, obesity hypoventilation syndrome is associated with serious cardiopulmonary comorbidities (e.g., pulmonary hypertension), metabolic diseases, and increased mortality [12-14].

Types of PAP Therapy That Can Be Used in OHS: CPAP, BPAPS, BPAP-ST, and VAPS In those OHS patients with compensated hypercapnic respiratory failure and predominant (severe) 
Table 2 Noninvasive ventilation (NIV) modes, settings, and clinical indications

\begin{tabular}{|c|c|c|}
\hline Mode & Settings & Clinical indications \\
\hline $\begin{array}{l}\text { Bilevel PAP (BPAP) } \\
\text { - Spontaneous (S) mode: the device senses pa- } \\
\text { tient's inhaling and exhaling flow and supplies } \\
\text { the IPAP and EPAP respectively. } \\
\text { - Spontaneous-timed (ST) mode: the device will } \\
\text { support and/or augment breaths initiated by the } \\
\text { patient and supply additional breaths should the } \\
\text { patient breath rate fall below the preset backup } \\
\text { rate. }\end{array}$ & $\begin{array}{l}\text { - Inspiratory pressure (IPAP) } \\
\text { - Expiratory pressure (EPAP) } \\
\text { - Spontaneous (S) mode: no backup rate } \\
\text { - Spontaneous-timed (ST) mode: backup respira- } \\
\text { tory rate. This ensures that the patient receives a } \\
\text { minimum number of breaths per minute. }\end{array}$ & $\begin{array}{l}\text { - Spontaneous (S) mode: to support and/or } \\
\text { augment breaths in patients with intact re- } \\
\text { spiratory drive and respiratory muscle } \\
\text { strength. } \\
\text { - Spontaneous-timed (ST) mode for patients } \\
\text { with impaired respiratory drive or neuro- } \\
\text { muscular disease with insufficient triggering } \\
\text { of IPAP. }\end{array}$ \\
\hline $\begin{array}{l}\text { Adaptive servoventilation (ASV) } \\
\text { - ASV mode self-adjusts pressures to deliver } \\
\text { anticyclical respiratory support to patient's } \\
\text { breathing pattern. }\end{array}$ & $\begin{array}{l}\text { - Maximum and minimum inspiratory pressures or } \\
\text { pressure support. } \\
\text { - Expiratory pressure (EPAP) (EPAP may be fixed } \\
\text { or in "auto" self-adjusting ranges to pneumati- } \\
\text { cally splint the upper airway: Min. EPAP and } \\
\text { Max. EPAP). } \\
\text { - Backup ventilatory rate and flow characteristics } \\
\text { may be adjusted or set to default factory } \\
\text { settings. }\end{array}$ & $\begin{array}{l}\text { - Treatment-emergent central sleep apnea. } \\
\text { - Opioid-induced central sleep apnea without } \\
\text { hypoventilation. }\end{array}$ \\
\hline $\begin{array}{l}\text { Volume-assure pressure support (VAPS) } \\
\text { - Feedback loop system which adjusts its pressures } \\
\text { to deliver a set tidal volume or alveolar } \\
\text { ventilation, guaranteeing a minute ventilation. }\end{array}$ & $\begin{array}{l}\text { - Target tidal volume or alveolar ventilation. } \\
\text { - Expiratory positive airway pressure (EPAP) } \\
\text { (EPAP may be fixed or in "auto" self-adjusting } \\
\text { ranges to pneumatically splint the upper airway: } \\
\text { Min. EPAP and Max. EPAP) } \\
\text { - Min. IPAP. } \\
\text { - Max. IPAP. } \\
\text { - Respiratory rate. } \\
\text { - Flow characteristics may also be set, but default } \\
\text { values are provided by factory. }\end{array}$ & $\begin{array}{l}\text { - In OHS patients who failed CPAP therapy. } \\
\text { - In OHS with predominant reduced } \\
\text { respiratory drive ("true Pickwickian } \\
\text { syndrome"). }\end{array}$ \\
\hline
\end{tabular}

$\mathrm{CPAP}=$ continuous positive airway pressure; IPAP $=$ inspiratory positive airway pressure; $\mathrm{EPAP}=$ expiratory positive airway pressure; Max. $=$ maximal; Min. $=$ minimal; $\mathrm{OHS}=$ obesity hypoventilation syndrome

OSA phenotype, CPAP therapy is considered the first-line therapy [15]. CPAP relieves OSA and ameliorates hypoventilation over an average of 3-month period [16]. Regarding NIV, BPAP-S and BPAP-ST have shown to be equally effective to CPAP in improving daytime hypercapnia and mortality $[15,17,18]$. In comparison to BPAP-ST, VAPS in ST mode has been shown to reach a larger improvement of $\mathrm{PaCO}_{2}$ levels and equal improvement in nocturnal oxyhemoglobin saturation, sleep quality, and health-related quality of life [19]. BPAP-ST and VAPS are equally effective as long as both modes are set to reach a similar amount of ventilatory support [19-21]. Based on current literature, NIV has not been shown to be superior to CAP to treat OHS patients with predominant (severe) OSA disease [15].

The literature of OHS patients with mild or non-OSA where central hypoventilation is the main mechanism ("true Pickwickian syndrome") is limited and the clinical impact of PAP therapy remains under investigation [22]. In this OHS phenotype, CPAP and BPAP-S therapy may be insufficient [23]. A recently published randomized trial indicated that VAPS was more effective than lifestyle modification alone (calorie-restricted diet and the maintenance of correct sleep hygiene and habits) in improving daytime $\mathrm{PaCO}_{2}$, sleepiness, and polysomnographic parameters in this population [24].
Therefore, in OHS patients with predominant lack of respiratory drive and persistent hypercapnia, a trial of BPAP-ST or VAPS is recommended [9].

In summary, based on OHS phenotype, we recommend starting CPAP therapy in OHS patients with predominant OSA. If hypoxia or hypercapnia persists while on CPAP, BPAP-S may be initiated for ventilatory support and to improve respiratory mechanics. For those OHS patients with mild or non-OSA but severe hypercapnia and typical REM sleep hypoventilation secondary to decreased respiratory drive, a NIV mode with backup rate such as BPAP-ST or VAPS is recommended.

\section{Sleep-Related Hypoventilation Due to Neuromuscular Diseases (NMD)}

Pathophysiology of NMD NMD can result in hypoventilation as a consequence of respiratory muscle insufficiency and/or dysfunction. These disorders adversely affect the transmission of respiratory signals (output) from the brainstem respiratory center to the respiratory muscles, resulting in insufficiency of respiratory muscle contraction. Hypoventilation is most pronounced during sleep as a consequence of sleep-related physiological hypoventilation in comparison to the awake state. 
Fig. 2 (A-D) Noninvasive ventilation waveforms. ASV = adaptive servoventilation; $\mathrm{CSA}=$ central sleep apnea; EPAP = expiratory positive airway pressure; IPAP = inspiratory positive airway pressure; IPAP min. = minimal inspiratory positive airway pressure; IPAP max. $=$ maximal inspiratory positive airway pressure; OSA = obstructive sleep apnea; $\mathrm{CSR}=$ Cheyne-Stokes respiration; PS = pressure support; $\mathrm{RR}=$ respiratory rate; $\mathrm{Vt}=$ tidal volume; $\mathrm{Vte}=$ expiratory tidal volume; VAPS $=$ volume-assured pressure support

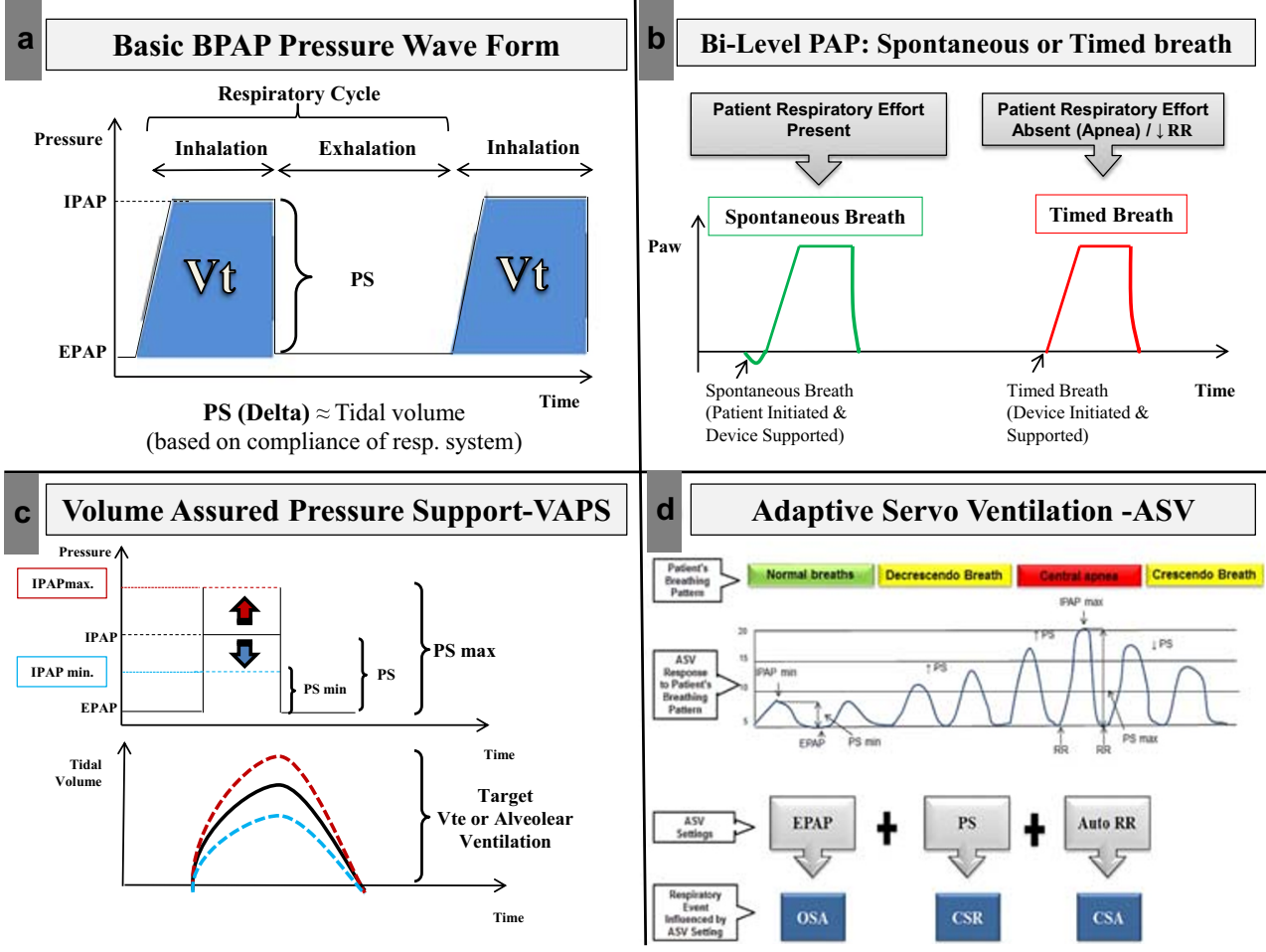

Although most extensively described in amyotrophic lateral sclerosis (ALS), experience on NIV to treat nocturnal alveolar hypoventilation due to neuromuscular disease extends to Duchenne muscular dystrophy, myotonic dystrophy, and acid maltase deficiency, among others.

In ALS patients, NIV has not only been shown to improve gas exchange and subjective sleep quality, but also quality of life and survival, particularly in those compliant with PAP therapy ( $\geq 4 \mathrm{~h}$ ) and those without severe bulbar dysfunction $[25,26]$. The decision to start PAP therapy in ALS patients is based on the combination of symptoms (orthopnea, sleep fragmentation, morning headaches, excessive daytime sleepiness), the rate of disease progression, and objective evidence of respiratory muscle insufficiency and/or dysfunction (forced vital capacity $<50 \%$ of predicted; maximal inspiratory pressure $<-60 \mathrm{~cm} \mathrm{H}_{2} \mathrm{O}$ or sniff nasal pressure $<40 \mathrm{~cm} \mathrm{H}_{2} \mathrm{O}$; $\mathrm{PaCO}_{2}>45 \mathrm{mmHg}$ ) [27].

PAP Therapy That Can Be Used: BPAP-ST and VAPS Besides treatment with riluzole, BPAP-ST is currently the only treatment option to increase survival in ALS. CPAP and BPAP-S have no role in securing ventilation in neuromuscular disease patients with acute and/or chronic respiratory failure.

In the NMD population, VAPS devices are also used based on the theoretical advantage of self-adjusting settings to match the disease progression. Although significant improvements in tidal volume are reached in those NMD patients using VAPS, no differences in number of apneas or hypopneas, saturation of oxygen, and oxygen desaturation index (number of oxygen desaturations of $\geq$ $4 \%$ per hour of total recording time) were noted when compared to BPAP-ST. Nocturnal gas exchange $(\mathrm{pH}$, $\mathrm{PaCO}_{2}$, nocturnal oxyhemoglobin saturation), sleep quality, and respiratory muscle strength were also similar [28-30].

In summary, under close monitoring and follow-up by trained providers, BPAP-ST with relatively low inspiratory pressure is the most commonly used NIV modality to treat NMD patients with chronic alveolar hypoventilation. VAPS is an alternative form of NPPV that is increasingly used in this population [28]. While there are theoretical potential benefits to dynamically adjust ventilatory support with VAPS in the setting of progressive respiratory failure, BPAP-ST continues to be widely accepted as standard of care. The role of VAPS is yet to be clarified by the current literature.

\section{Central Sleep Apnea Syndromes}

CSAS are characterized by a group of sleep-related breathing disorders associated with decreased or absent respiratory efforts (apneic events), combined with symptoms such as excessive daytime sleepiness and/or sleep fragmentation. In these disorders, respiratory instability is most often the result of overresponse (hyperventilation) or underresponse (apnea) of the respiratory control system to minimal changes in nocturnal $\mathrm{pCO}_{2}$ (high loop gain) $[8,31]$. 


\section{Central Sleep Apnea with Cheyne-Stokes Respiration (CSA-CSR)}

\section{Pathophysiology of CSA-CSR}

CSA-CSR is related to unstable breathing caused by high loop gain, an excessive magnitude of respiratory drive response to a given (proportionally) minor respiratory disturbance. Loop gain has three components: circulatory time, plant gain, and controller gain. The prolonged lung to brain circulatory delay is commonly seen in congestive heart failure (CHF) due to reduced cardiac output. In CHF, the circulatory delay is doubled (10-20 s). Controller gain is related to chemosensitivity (heightened ventilatory response to minor $\mathrm{CO}_{2}$ fluctuations), while plant gain is related to the modification in $\mathrm{pCO}_{2}$ resulting from a given change in ventilation. High loop gain predisposes to hyperventilation (overshoot) and subsequent lowering of $\mathrm{pCO}_{2}$ below the apneic threshold which is elevated during NREM sleep. When carbon dioxide drops below the apneic threshold, a central apnea event (undershoot) will occur and last until the carbon dioxide increases above the threshold. Therefore, $\mathrm{pCO}_{2}$ levels oscillate above and below the apneic threshold, thereby causing the typical cyclical hyperventilation followed by central apnea pattern that defines CSA-CSR $[8,32]$.

Although CSA-CSR is more prevalent in CHF patients, it can also be encountered in other medical disorders such as acute ischemic stroke and renal failure [33]. In CHF patients, CSACSR can be found in either systolic dysfunction, known as heart failure with reduced ejection fraction (HFrEF), or diastolic left ventricular dysfunction, known as heart failure with preserved ejection fraction (HFpEF) [34]. In the HFrEF, CSA-CSR is recognized as a marker of disease severity and impaired prognosis (e.g., increased mortality and hospitalization).

\section{PAP Therapies That Can Be Used: CPAP, BPAP-ST, and ASV}

If underlying heart failure is present, cardiac optimization with guideline-directed therapy should be prioritized before PAP therapy is considered. The decision to treat CSA with PAP therapy remains controversial based on current data. If PAP therapy is considered, careful selection of the PAP mode (e.g., CPAP vs BPAP-ST vs ASV) should be based on symptomatology, clinical acuity, and cardiovascular status (e.g., left ventricular ejection fraction) [35].

Although CPAP is considered the initial PAP therapy for symptomatic CHF patients with persistent CSA, contradictory information exists regarding survival (transplant-free survival) in patients with HFrEF [36]. CPAP improves hemodynamics (e.g., left ventricular ejection fraction), with a trend towards decreasing combined mortality-cardiac transplantation rate in CHF with CSA-CSR patients, particularly in patients who comply with therapy and achieve a clinical significant suppression of the respiratory disturbance (reduction of apnea hypopnea index to $<15$ events per hour) [37].

There is consistent evidence that BPAP-ST is superior to CPAP in suppressing respiratory disturbances and is equally effective to ASV in improving left ventricular ejection fraction in patients with $\mathrm{HFrEF}$ and CSA [38]. Since the publication of the SERVEHF trial, ASV use is currently contraindicated in CHF patients with a left ventricular ejection fraction of $\leq 45 \%$ and moderate to severe CSA due to increased risk of all-cause and cardiovascular mortality $[39,40]$. Based on current clinical guidelines, ASV still remains an option to use in CHF patients with a left ventricular ejection fraction $>45 \%$, HFpEF, and treatment-emergent central sleep apnea as well as in cases of CSA-CSR associated with acute stroke or renal failure [41].

Consistent evidence has demonstrated that the development of CSAS in patients with CHF is a poor prognostic indicator and a risk factor for cardiovascular mortality. However, it remains unclear what effect PAP therapies have on patients with CHF. To date, all major randomized clinical trials have failed to demonstrate a survival benefit with PAP therapy and one major study investigating the use of ASV demonstrated harm in HFrEF patients with predominant CSAS [39].

\section{Central Sleep Apnea Due to Opioid Use}

\section{Pathophysiology of CSA Due to Opioids}

All opioids inhibit $\mu$-opioid receptors distributed on respiratory neurons throughout the central and peripheral nervous system. Among the most important opioid-sensitive areas in respiratory centers are the following: (1) pre-Bötzinger complex, the principal kernel responsible for generating inspiration and for central chemoreception of $\mathrm{CO}_{2}$; (2) glomus cells of the carotid body, responsible for breath-by-breath control by providing rapid feedback from the periphery to the central nervous system regarding concentrations of oxygen, carbon dioxide, and hydrogen/PH; (3) bulbospinal inspiratory and expiratory premotor neurons that project to the phrenic, intercostal, and abdominal motoneurons; and (4) the hypoglossal motor nucleus necessary for maintaining upper airway patency during sleep [42-44]. Therefore, opioids have the potential to affect breathing frequency, tidal volume, rhythm, upper airway patency, and chemosensitivity to $\mathrm{CO}_{2}$ and $\mathrm{O}_{2}$ changes. Clinically, this may translate into changes of breathing pattern (ataxia or irregular vs regular), presence of sleep-related breathing disorders (central and/or obstructive apneas and hypopneas), gas exchange (hypoxia and hypercapnia), or a combination of them. As the effects of opioids on central apneas are dose-dependent, discontinuation or reduction of the dose of opioid as tolerated is considered the first-line therapy $[45,46]$. 
PAP Therapies That Can Be Used: CPAP, BPAP-S, BPAP-ST, and ASV

Studies assessing the effectiveness of PAP therapy in chronic opioid users have shown conflicting results. Although CPAP may reduce the number of respiratory events, generally by controlling obstructive respiratory events, centrally mediated sleep-disordered breathing may not only persist but also increase during the implementation of CPAP in this population [47].

Although ASV is commonly prescribed to chronic opioid users with predominant CSA, conflicting data exist about the role of ASV in this group. One study did not show ASV efficacy, likely related to suboptimal titration of the device [48]. In two other studies with optimal titrations, ASV was effective in the majority of cases $[49,50]$. In cases where CPAP and ASV are ineffective or if nocturnal hypercapnia develops, BPAP-ST should be considered for ventilation, particularly in patients with hypercapnic respiratory failure.

In summary, if discontinuation or reduction of opiate dose is not feasible or effective, we would recommend a polysomnographic study with NIV titration. In those chronic opioid users with predominant CSA, ASV has shown to be highly effective once the device is titrated appropriately. If ASV is ineffective or if alveolar hypoventilation persists despite resolution of CSA, BPAP-ST may be a better option to maximize ventilatory support in these patients.

\section{Treatment-Emergent Central Sleep Apnea (Formerly Known as Complex Sleep Apnea Syndrome)}

Treatment-emergent central sleep apnea (TECSA) is defined by the AASM as the emergence (or persistence) of CSA during PAP therapy after elimination of predominantly obstructive respiratory events. However, TECSA is a dynamic phenomenon during which CSA may not persist over time in some patients [51]. Therefore, two therapeutic phenotypes can be identified: those patients with "transient CSA" which resolve with continued CPAP use and those with "treatmentpersistent" emergent CSA who will benefit from BPAP-ST or ASV therapy. Agreement on initial device mode therapy (CPAP vs ASV) continues to be controversial due to difficulties in identifying these two phenotypes at PAP initiation during polysomnography.

\section{Pathophysiology of TECSA}

The mechanism(s) by which CAs develop after the elimination of obstructive events during treatment with CPAP remain unclear, though possible causes include higher CPAP than needed to control obstructive events, postarousal CSA, readaptation of the loop gain after resolution of upper airway obstruction, associated comorbidities/medications (e.g., $\mathrm{CHF}$ or opioids), and unmasking of previously existing centralmediated apneas and hypopneas. It is possible that by eliminating the contributing obstructive component, CPAP therapy could expose central hypopneas and centrally originating mixed apneas, classified as obstructive on initial polysomnography, as centrally mediated. Through the mechanisms of improved efficiency of $\mathrm{CO}_{2}$ clearance, CPAP could also aggravate central hypopneas (misclassified as obstructive events) into frank CAs. The net effect of this would be to "unmask" central events, increasing the CA index without actually creating new events. This mechanism could also explain the development of CSA after treatment with oral appliance therapy or upper airway surgery. Most recently, several endotypic/phenotypic traits of OSA patients have been identified based on their leading pathophysiologic pathways, including OSA patients with increased loop gain. Although the role of exaggerated loop gain in the pathogenesis of CSA in $\mathrm{CHF}$ has been well established (see the "Central Sleep Apnea with Cheyne-Stokes Respiration (CSA-CSR)" section). It has also been shown to contribute to the severity of OSA and probably contributing to the pathogenesis of TECSA [52].

\section{PAP Therapies That Can Be Used: CPAP, BPAP-ST, and ASV}

The literature in this area is controversial, mostly based on differences in TECSA operational definition(s) used in these studies. Some studies included primarily patients with almost pure CSA-CSR, while some cohort studies and randomized controlled studies focused on coexisting OSA and CSA. Retrospective studies suggest that the majority of patients will stabilize their breathing patterns on CPAP, though with possible significant dropout rates based on poor CPAP tolerance [51, $53,54]$. While BPAP-ST mode may offer an alternative to CPAP or ASV, residual sleep fragmentation may still be present, thereby increasing the risk of low therapeutic compliance [55].

Unfortunately, clinical or polysomnographic criteria to identify in advance the phenotype of CPAP nonresponders who may benefit from ASV therapy in TECSA are not well defined. The phenotypic group of TECSA patients with persistently elevated CSA events may benefit from effective therapies focused on eliminating CSA. A prospective trial has shown that over $90 \%$ of those treated with ASV show both initial and long-term control of CSA [55]. In comparison to CPAP and BPAP-ST, ASV treatment in patients with TECSA has resulted in a significantly greater decrease of the respiratory events in all positions and stages of sleep, lower sleep fragmentation, and higher percentage of deep sleep (REM sleep) as well as improvement in daytime alertness [56].

In summary, we recommend CPAP as initial mode of PAP therapy with close longitudinal follow-up. For CPAP nonresponders or for those TECSA patients unable to have a close clinical follow-up, we recommend proceeding directly to 
ASV therapy. ASV effectively improves treatment-persistent CSA compared to oxygen, CPAP, and BPAP-ST.

\section{Conclusions}

The field of PAP therapy has dramatically changed after the introduction of highly sophisticated devices such as the BPAP-ST, VAPS, and ASV, with algorithms capable to adapt and support a wide variety of sleep-related breathing disorders. With "learning capabilities" of these new devices to selfadjust their own ventilatory settings, combined with a full set of automatic functions for respiratory synchrony, these modes may become the new standard in ventilatory therapy for sleeprelated hypoventilation disorders or central sleep apnea syndromes. Further investigation is needed to understand which phenotypes of sleep-related breathing disorders may benefit from NIV treatment. Also, studies on clinical outcomes and cost-effectiveness are needed to understand the role of these new technologies in our daily practice.

Required Author Forms Disclosure forms provided by the authors are available with the online version of this article.

\section{References}

1. Sullivan CE, Issa FG, Berthon-Jones M, Eves L. Reversal of obstructive sleep apnoea by continuous positive airway pressure applied through the nares. Lancet. 1981;1(8225):862-865.

2. Andersson $B$, Lundin $S$, Lindgren $S$, Stenqvist $O$, Odenstedt Hergès $\mathrm{H}$. End-expiratory lung volume and ventilation distribution with different continuous positive airway pressure systems in volunteers. Acta Anaesthesiol Scand 2011;55(2):157-164.

3. Sanders MH, Kern N. Obstructive sleep apnea treated by independently adjusted inspiratory and expiratory positive airway pressures via nasal mask. Physiologic and clinical implications. Chest. 1990;98(2):317-324.

4. Selim BJ, Wolfe L, Coleman JM, 3rd, Dewan NA. Initiation of noninvasive ventilation for sleep related hypoventilation disorders: advanced modes and devices. Chest. 2018;153(1):251-265.

5. International Classification of Sleep Disorders, 3rd ed. American Academy of Sleep Medicine, Darien, IL 2014. 2014(3rd ed).

6. Selim BJ, Junna MR, Morgenthaler TI. Therapy for sleep hypoventilation and central apnea syndromes. Curr Treat Options Neurol 2012;14 (5):427-437.

7. Selim B, Ramar K. Advanced positive airway pressure modes: adaptive servo ventilation and volume assured pressure support. Expert Rev Med Devices 2016;13(9):839-851.

8. Javaheri S. Central sleep apnea. Clin Chest Med 2010;31 (2):235248.

9. Mokhlesi B, Masa JF, Brozek JL, Gurubhagavatula I, Murphy PB, Piper AJ, et al. Evaluation and management of obesity hypoventilation syndrome. An Official American Thoracic Society Clinical Practice Guideline. Am J Respir Crit Care Med 2019;200(3):e6-e24.

10. Berger KI, Ayappa I, Sorkin IB, Norman RG, Rapoport DM, Goldring RM. Postevent ventilation as a function of $\mathrm{CO}(2)$ load during respiratory events in obstructive sleep apnea. J Appl Physiol. 2002;93(3):917-924.

11. Pépin JL, Timsit JF, Tamisier R, Borel JC, Lévy P, Jaber S. Prevention and care of respiratory failure in obese patients. Lancet Respir Med 2016;4(5):407-418.

12. Jennum P, Ibsen R, Kjellberg J. Morbidity prior to a diagnosis of sleep-disordered breathing: a controlled national study. J Clin Sleep Med 2013;9(2):103-108.

13. Basoglu OK, Tasbakan MS. Comparison of clinical characteristics in patients with obesity hypoventilation syndrome and obese obstructive sleep apnea syndrome: a case-control study. Clin Respir J 2014;8(2):167-174.

14. Nowbar S, Burkart KM, Gonzales R, Fedorowicz A, Gozansky WS, Gaudio JC, et al. Obesity-associated hypoventilation in hospitalized patients: prevalence, effects, and outcome. Am J Med 2004;116(1):1-7.

15. Afshar M, Brozek JL, Soghier I, Kakazu MT, Wilson KC, Masa JF, et al. The role of positive airway pressure therapy in adults with obesity hypoventilation syndrome. A systematic review and metaanalysis. Ann Am Thorac Soc 2020;17(3):344-360.

16. Piper AJ, Wang D, Yee BJ, Barnes DJ, Grunstein RR. Randomised trial of CPAP vs bilevel support in the treatment of obesity hypoventilation syndrome without severe nocturnal desaturation. Thorax. 2008;63(5):395-401.

17. Masa JF, Mokhlesi B, Benítez I, Gomez de Terreros FJ, SánchezQuiroga M, Romero A, et al. Long-term clinical effectiveness of continuous positive airway pressure therapy versus non-invasive ventilation therapy in patients with obesity hypoventilation syndrome: a multicentre, open-label, randomised controlled trial. Lancet. 2019;393(10182):1721-1732.

18. Royer CP, Schweiger C, Manica D, Rabaioli L, Guerra V, Sbruzzi G. Efficacy of bilevel ventilatory support in the treatment of stable patients with obesity hypoventilation syndrome: systematic review and meta-analysis. Sleep Med 2019;53:153-164.

19. Storre JH, Seuthe B, Fiechter R, Milioglou S, Dreher M, Sorichter $\mathrm{S}$, et al. Average volume-assured pressure support in obesity hypoventilation: a randomized crossover trial. Chest. 2006;130(3): 815-821.

20. Masa JF, Corral J, Alonso ML, Ordax E, Troncoso MF, Gonzalez $M$, et al. Efficacy of different treatment alternatives for obesity hypoventilation syndrome. Pickwick study. Am J Respir Crit Care Med 2015;192(1):86-95.

21. Janssens JP, Pautex S, Hilleret H, Michel JP. Sleep disordered breathing in the elderly. Aging Clin Exp Res 2000;12(6):417-429.

22. Masa JF, Mokhlesi B, Benítez I, Sánchez-Quiroga M, Gomez de Terreros FJ, Corral J, Romero A, et al. Spanish Sleep Network. Cost-effectiveness of positive airway pressure modalities in obesity hypoventilation syndrome with severe obstructive sleep apnoea. Thorax. 2020;75(6):459-467. https://doi.org/10.1136/thoraxjnl2019-213622.

23. Contal O, Adler D, Borel JC, Espa F, Perrig S, Rodenstein D, et al. Impact of different backup respiratory rates on the efficacy of noninvasive positive pressure ventilation in obesity hypoventilation syndrome: a randomized trial. Chest. 2013;143(1):37-46.

24. Masa JF, Corral J, Caballero C, Barrot E, Terán-Santos J, AlonsoÁlvarez ML, et al. Non-invasive ventilation in obesity hypoventilation syndrome without severe obstructive sleep apnoea. Thorax. 2016;71(10):899-906.

25. Bourke SC, Tomlinson M, Williams TL, Bullock RE, Shaw PJ, Gibson GJ. Effects of non-invasive ventilation on survival and quality of life in patients with amyotrophic lateral sclerosis: a randomised controlled trial. Lancet Neurol 2006;5(2):140-147.

26. Radunovic A, Annane D, Rafiq MK, Brassington R, Mustfa N. Mechanical ventilation for amyotrophic lateral sclerosis/motor neuron disease. Cochrane Database Syst Rev. 2017;10(10):Cd004427. 
27. Miller RG, Jackson CE, Kasarskis EJ, England JD, Forshew D, Johnston W, et al. Practice parameter update: the care of the patient with amyotrophic lateral sclerosis: drug, nutritional, and respiratory therapies (an evidence-based review): report of the Quality Standards Subcommittee of the American Academy of Neurology. Neurology. 2009;73(15):1218-1226.

28. Patel SI, Gay P, Morgenthaler TI, Olson EJ, Shamoun FE, Kashyap $\mathrm{R}$, et al. Practical implementation of a single-night split-titration protocol with BPAP-ST and AVAPS in patients with neuromuscular disease. J Clin Sleep Med 2018;14(12):2031-2035.

29. Nicholson TT, Smith SB, Siddique T, Sufit R, Ajroud-Driss S, Coleman JM, 3rd, et al. Respiratory pattern and tidal volumes differ for pressure support and volume-assured pressure support in amyotrophic lateral sclerosis. Ann Am Thorac Soc 2017;14(7):11391346.

30. Crescimanno G, Marrone O, Vianello A. Efficacy and comfort of volume-guaranteed pressure support in patients with chronic ventilatory failure of neuromuscular origin. Respirology. 2011;16(4): 672-679.

31. Aurora RN, Chowdhuri S, Ramar K, Bista SR, Casey KR, Lamm CI, et al. The treatment of central sleep apnea syndromes in adults: practice parameters with an evidence-based literature review and meta-analyses. Sleep. 2012;35(1):17-40.

32. Naughton MT. Respiratory sleep disorders in patients with congestive heart failure. J Thorac Dis 2015;7(8):1298-1310.

33. Johnson KG, Johnson DC. Frequency of sleep apnea in stroke and TIA patients: a meta-analysis. J Clin Sleep Med 2010;6(2):131-137.

34. Sekizuka H, Osada N, Miyake F. Sleep disordered breathing in heart failure patients with reduced versus preserved ejection fraction. Heart Lung Circ 2013;22(2):104-109.

35. Javaheri S, Brown LK, Khayat RN. Update on apneas of heart failure with reduced ejection fraction: emphasis on the physiology of treatment: part 2: central sleep apnea. Chest. 2020;57(6):16371646. https://doi.org/10.1016/j.chest.2019.12.020.

36. Bradley TD, Logan AG, Kimoff RJ, Sériès F, Morrison D, Ferguson K, et al. Continuous positive airway pressure for central sleep apnea and heart failure. N Engl J Med 2005;353(19):20252033.

37. Arzt M, Floras JS, Logan AG, Kimoff RJ, Series F, Morrison D, et al. Suppression of central sleep apnea by continuous positive airway pressure and transplant-free survival in heart failure: a post hoc analysis of the Canadian Continuous Positive Airway Pressure for Patients with Central Sleep Apnea and Heart Failure Trial (CANPAP). Circulation. 2007;115(25):3173-3180.

38. Fietze I, Blau A, Glos M, Theres H, Baumann G, Penzel T. Bi-level positive pressure ventilation and adaptive servo ventilation in patients with heart failure and Cheyne-Stokes respiration. Sleep Med 2008;9(6):652-659.

39. Cowie MR, Woehrle H, Wegscheider K, Angermann C, d'Ortho MP, Erdmann E, et al. Adaptive servo-ventilation for central sleep apnea in systolic heart failure. N Engl J Med 2015;373(12):10951105.

40. Woehrle H, Cowie MR, Eulenburg C, Suling A, Angermann C, d'Ortho MP, et al. Adaptive servo ventilation for central sleep apnoea in heart failure: SERVE-HF on-treatment analysis. Eur Respir J. 2017;50(2):1601692. https://doi.org/10.1183/13993003.016922016.

41. Aurora RN, Bista SR, Casey KR, Chowdhuri S, Kristo DA, Mallea $\mathrm{JM}$, et al. Updated adaptive servo-ventilation recommendations for the 2012 AASM guideline: "the treatment of central sleep apnea syndromes in adults: practice parameters with an evidence-based literature review and meta-analyses". J Clin Sleep Med 2016;12(5): 757-761.

42. Montandon G, Qin W, Liu H, Ren J, Greer JJ, Horner RL. PreBotzinger complex neurokinin-1 receptor-expressing neurons mediate opioid-induced respiratory depression. J Neurosci 2011;31(4):1292-1301.

43. Teichtahl H, Wang D, Cunnington D, Quinnell T, Tran H, Kronborg I, et al. Ventilatory responses to hypoxia and hypercapnia in stable methadone maintenance treatment patients. Chest. 2005;128(3):1339-1347.

44. Hajiha M, DuBord MA, Liu H, Horner RL. Opioid receptor mechanisms at the hypoglossal motor pool and effects on tongue muscle activity in vivo. J Physiol 2009;587(Pt 11):2677-2692.

45. Walker JM, Farney RJ, Rhondeau SM, Boyle KM, Valentine K, Cloward TV, et al. Chronic opioid use is a risk factor for the development of central sleep apnea and ataxic breathing.[Erratum appears in J Clin Sleep Med. 2007 Oct 15;3(6):table of contents]. J Clin Sleep Med 2007;3(5):455-461.

46. Rose AR, Catcheside PG, McEvoy RD, Paul D, Kapur D, Peak E, et al. Sleep disordered breathing and chronic respiratory failure in patients with chronic pain on long term opioid therapy. J Clin Sleep Med 2014;10(8):847-852.

47. Javaheri S, Harris N, Howard J, Chung E. Adaptive servoventilation for treatment of opioid-associated central sleep apnea. J Clin Sleep Med 2014;10(6):637-643.

48. Farney RJ, Walker JM, Boyle KM, Cloward TV, Shilling KC. Adaptive servoventilation (ASV) in patients with sleep disordered breathing associated with chronic opioid medications for nonmalignant pain. J Clin Sleep Med 2008;4(4):311-319.

49. Ramar K, Ramar P, Morgenthaler TI. Adaptive servoventilation in patients with central or complex sleep apnea related to chronic opioid use and congestive heart failure. J Clin Sleep Med 2012;8 (5):569-576.

50. Javaheri S, Malik A, Smith J, Chung E. Adaptive pressure support servoventilation: a novel treatment for sleep apnea associated with use of opioids. J Clin Sleep Med 2008;4(4):305-310.

51. Liu D, Armitstead J, Benjafield A, Shao S, Malhotra A, Cistulli PA, et al. Trajectories of Emergent Central Sleep Apnea During CPAP Therapy. Chest. 2017;152(4):751-760.

52. Dempsey JA, Skatrud JB. Apnea following mechanical ventilation may be caused by nonchemical neuromechanical influences. Am J Respir Crit Care Med 2001;163(6):1297-1298.

53. Cassel W, Canisius S, Becker HF, Leistner S, Ploch T, Jerrentrup A, et al. A prospective polysomnographic study on the evolution of complex sleep apnoea. Eur Respir J 2011;38(2):329-337.

54. Pépin JL, Woehrle H, Liu D, Shao S, Armitstead JP, Cistulli PA, et al. Adherence to positive airway therapy after switching from CPAP to ASV: a big data analysis. J Clin Sleep Med 2018;14(1): 57-63.

55. Morgenthaler TI, Kuzniar TJ, Wolfe LF, Willes L, McLain WC, 3rd, Goldberg R. The complex sleep apnea resolution study: a prospective randomized controlled trial of continuous positive airway pressure versus adaptive servoventilation therapy. Sleep. 2014;37(5):927-934.

56. Dellweg D, Kerl J, Hoehn E, Wenzel M, Koehler D. Randomized controlled trial of noninvasive positive pressure ventilation (NPPV) versus servoventilation in patients with CPAP-induced central sleep apnea (complex sleep apnea). Sleep. 2013;36(8):1163-1171.

Publisher's Note Springer Nature remains neutral with regard to jurisdictional claims in published maps and institutional affiliations. 